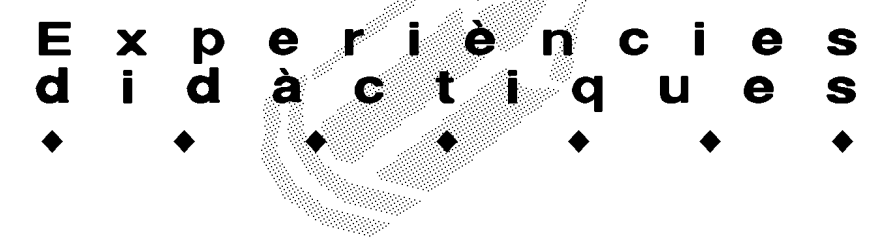

\title{
ASPECTES BÀSICS DE L'ABSTRACCIÓ EN MATEMÀTIQUES A L'EDUCACIÓ INFANTIL SEGONS EL MODEL CATALÀ I FRANCÈS
}

\author{
Montserrat Moreno Martínez, Jordi Icart Gomis, Àngels Oller Julian, Lina Tomàs Valldepérez i Vanessa \\ Vila Garrit, estudiants de 3r d'Educació Infantil. Ensenyament de Mestres. URV
}

\section{L’abstracció}

En l'àmbit de les matemàtiques l'abstracció és la capacitat de construir la representació mental de les nocions treballades sense tenir la necessitat de suports manipulatius i/o gràfics per a la seva comprensió. Un dels objectius més importants de les matemàtiques és el d'afavorir l'estructuració del pensament abstracte.

L'abstracció de les nocions matemàtiques s'aconsegueix de forma gradual al llarg de l'etapa d'educació infantil. En el primer cicle el nen/a experimentarà amb els objectes que I 'envolten, i descobrirà propietats com la mida, el color... En el segon cicle el nen/a passarà d'un pensament egocèntric a un de lògic, on atribuirà noves qualitats als objectes. Així, agruparà, compararà, ordenarà... utilitzant les formes, colors i la mesura. En conseqüència, l'educació matemàtica ha de potenciar el pensament abstracte i les diferents formes d'abstracció i operació mental. Per arribar a tenir una bona capacitat d'abstracció, s'hauran de donar les condicions necessàries per a realitzar un pensament abstracte, independent i crític.

Els objectius de les matemàtiques al darrer curs del segon cicle d'educació infantil (5-6 anys), són, entre d'altres: ajudar el nen a construir el seu pensament i poder-lo aplicar a la vida quotidiana, afavorir la construcció d'esquemes de coneixement cada cop més coherents, proporcionar el pensament intuïtiu i els mètodes per arribar a una estructura matemàtica, crear amb aquesta estructura les bases per a l'accés matemàtic posterior...

L'etapa de $0-6$ anys és una de les més importants per a desenvolupar l'estructuració del pensament i la formació de les estructures mentals bàsiques. Per tant, s'han de potenciar més les activitats de formació del pensament.

La matemàtica consta de tres grans etapes: l'etapa de la manipulació, de la representació i de l'abstracció. Centrem aquest article en la tercera etapa: l'abstracció.

El nostre objectiu és arribar a conèixer com es porta a la pràctica l'abstracció en les nocions matemàtiques d'educació infantil a partir de la comparació de dos llibres de text de matemàtiques de Catalunya i França: Comptar i escriure i Maternelle.

\section{Marc teòric}

Molts investigadors en psicologia de l'educació, pedagogia, didàctica... han mostrat un gran interès en l'estudi de com els nens/es assoleixen els conceptes matemàtics i científics.

El principi central de la teoria de Piaget sobre la construcció del coneixement és l'equilibració. Considera que la manera de conèixer el món que ens envolta, i per tant el progrés de l'estructura del pensament, no és degut a una suma de petits aprenentatges successius, sinó que es produeix mitjançant un procés d'equilibració, pel qual les persones aprenem quan ens enfrontem a una situació d'equilibri cognitiu que es produeix quan no coincideixen les nostres concepcions sobre la realitat $i$ el que realment està passant. Aquesta equilibració es porta a terme mitjançant dos processos íntimament relacionats i dependents, que són l'assimilació i l'acomodació. Quan un individu s'enfronta a una situació, en particular a un problema matemàtic, intenta assimilar aquesta situació a esquemes cognitius ja existents. Intenta resoldre el problema mitjançant els coneixements que ja té. Com a resultat de l'assimilació, l'esquema cognitiu existent es reconstrueix per acomodar la situació. És a dir, el binomi assimilació-acomodació produeix en els individus una reestructuració i reconstrucció dels esquemes cognitius existents. D'aquesta manera podem dir que per a Piaget l'alumne aprèn principalment per descobriment, en un procés constant de relació amb el medi i a través d'un continu entre l'assimilació i l'acomodació.

L'abstracció reflexiva és un terme central en la teoria de la construcció del coneixement. Piaget anomena així l'abstracció que parteix de les accions i no dels objectes. L'abstracció reflexiva comporta dos moments insepa- 


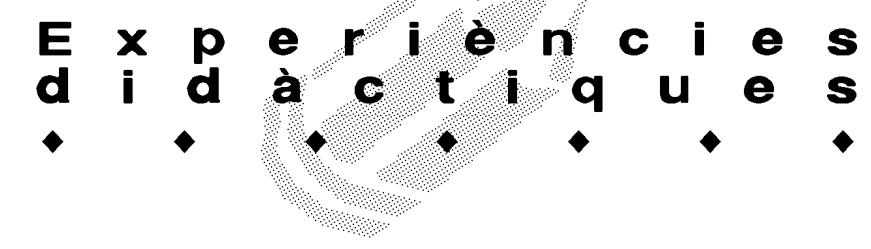

rables: un procés de reflexió, el qual fa passar el que es troba en un pla inferior a un altre superior, i un producte de la reflexió, una 'reflexió' en el sentit mental, que permet una reorganització cognitiva sobre el nou pla. En el pla inferior les accions i operacions es realitzen sobre objectes concrets, físics o imaginats, mentre que en el pla superior les accions i operacions interioritzades actuen sobre objectes abstractes i les coordina per formar noves accions que donen lloc a nous objectes. Per tant, l'abstracció reflexiva consisteix a traduir una successió d'actes materials en un sistema d'operacions interiorizades, on les seves estructures es comprenguin en un acte simultani.

\section{Enfocament constructivista}

L'enfocament constructivista fa referència a la convergència entre l'aprenentatge escolar, entès com un procés de construcció del coneixement, i l'ensenyament com un ajut a aquest procés de construcció. En la concepció de les matemàtiques i l'enfocament constructivista hi ha un cert paral-lelisme, el qual té relació amb la importància que es dóna als significats (en aquest cas, al coneixement matemàtic i a la seva utilització) i al fet de considerar la seva construcció com una activitat humana immersa en una cultura determinada.

La nostra actuació com a mestres ha d'estar guiada per la funció d'ajuda al procés de construcció del coneixement. No es tracta d'entendre el paper del mestre com el d'aquella persona que transmet els coneixements als seus alumnes mitjançant explicacions clares i precises, sinó com el d'un mediador que guia l'aprenentatge, que dissenya entorns i activitats per tal que els alumnes trobin oportunitats per construir els seus coneixements i anar-los integrant. Així, cal que el mestre, segons els principis generals del constructivisme, s'ocupi principalment de:

- Donar significat als continguts i als problemes.

- Proporcionar models alternatius de representació dels objectes matemàtics.

- Seqüenciar les activitats perquè siguin un suport real al procés constructiu del coneixement matemàtic.

- Promoure situacions d'aprenentatge que possibilitin la interacció entre mestre i alumne, i entre iguals.

- Interpretar i utilitzar els errors com a punt de referència de l'aprenentatge.

- Utilitzar l'avaluació com a eina al servei de l'aprenentatge.

En definitiva, cal que el mestre reguli el procés de cessió de la responsabilitat, donant als alumnes oportunitats en la presa de decisions, entenent els dubtes que sorgeixin, les dificultats i els errors com a part indispensable del procés educatiu. L'alumne ha de tenir una actuació participativa, verbalitzar les observacions que $\mathrm{fa}$, actuar de manera autònoma relativitzant la dependència de l'adult...

El nen/a, durant el període de l'activitat representativa, comença amb preconceptes que procedeixen de les percepcions i el contacte real amb els objectes. Però molt aviat comença a discriminar, a abstraure i a generalitzar mitjançant les dades de la realitat.

Un concepte consisteix en la generalització respecte a una sèrie de dades relacionades. Ara bé, els processos de generalització estan Iligats a l'abstracció. En la formació dels conceptes matemàtics, cal distingir entre l'abstracció simple i l'abstracció reflexiva.

L'abstracció simple és la que es dóna a partir de les propietats que hi ha als objectes. Mitjançant aquesta abstracció, tot el que fa el nen és centrar-se en una determinada propietat de l'objecte, ignorant les altres. A l'abstracció reflexiva, el que s'abstrau no és l'observable, sinó que es descobreixen propietats mitjançant les accions (comparar, agrupar, separar, ordenar...) que es fan sobre els objectes.

L'activitat de manipulació és, durant l'etapa d'educació infantil, un mitjà privilegiat per estimular la veritable activitat

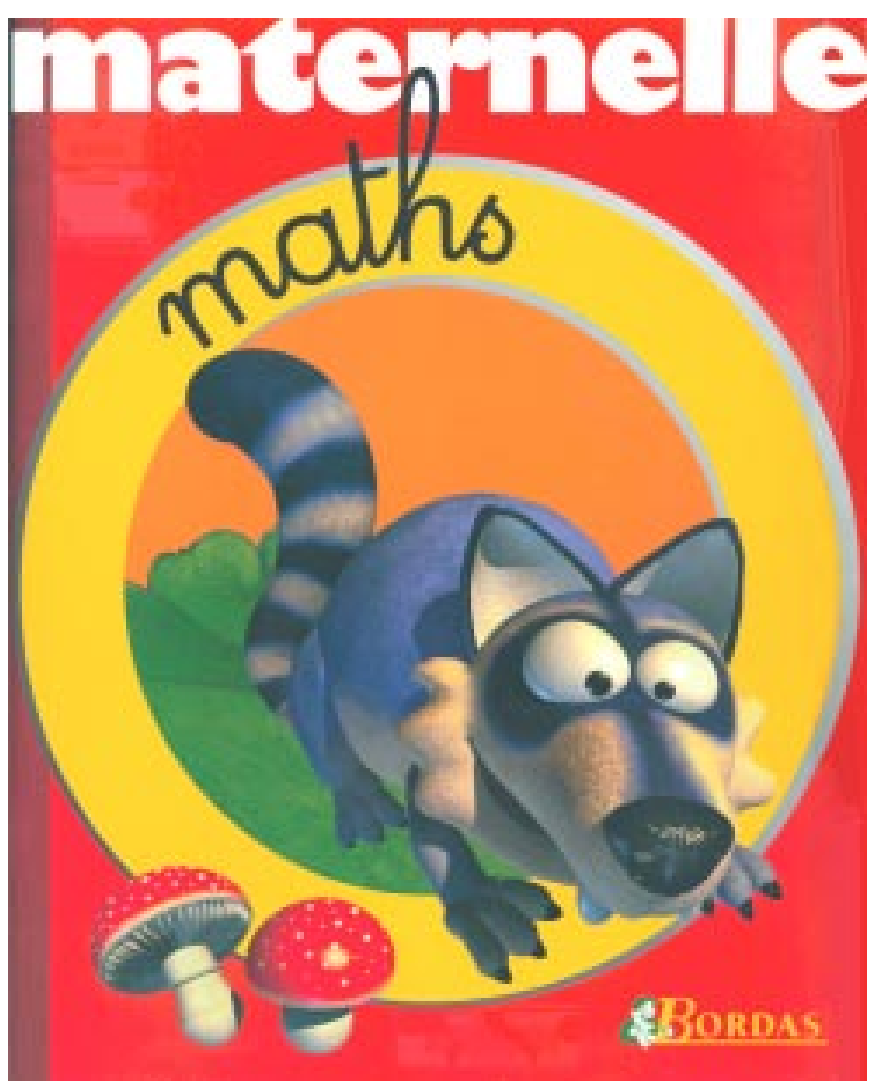




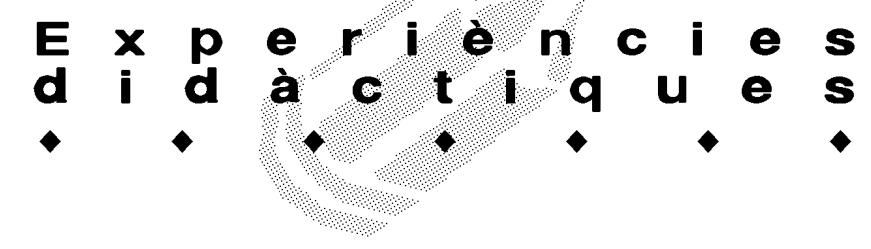

mental. En l'abstracció, per tal que el que fem sigui realment un aprenentatge matemàtic, cal seguir un procés. Entre les prioritats a tenir presents, caldria destacar:

- Només a partir de la vivenciació a través de situacions problemàtiques d'interpretació d'accions, el nen/a adquireix la comprensió del que signifiquen les operacions i detecta les problemàtiques que això origina. Posteriorment, cal engegar un procés d'aprofundiment en el coneixement conceptual a partir de la manipulació.

- Inicialment ens hauria d'interessar la comprensió conceptual sense cap mena de necessitat de priorització dels resultats.

- No s'haurien de centrar les descobertes en l'ús exclusiu d'un únic material. Seria molt important aplicar els mateixos plantejaments amb diferents materials per tal que la descoberta s'entengui com una llei general i no depenent de cap material.

\begin{tabular}{|l|l|}
\hline \multicolumn{2}{|c|}{ PRESENTACIÓ DE L'ACTIVITAT } \\
\hline \multicolumn{1}{|c|}{ Ilibre català } & \multicolumn{1}{c|}{ Ilibre francès } \\
\hline $\begin{array}{l}\text { Les activitats estan represen- } \\
\text { tades mitjançant fotografies } \\
\text { reals dels objectes. }\end{array}$ & $\begin{array}{l}\text { Les activitats estan presenta- } \\
\text { des mitjançant dibuixos amb } \\
\text { colors molt atractius. }\end{array}$ \\
\hline $\begin{array}{l}\text { Les fitxes no tenen cap títol } \\
\text { que especifiqui quins són els } \\
\text { continguts que s'estan } \\
\text { treballant. }\end{array}$ & $\begin{array}{l}\text { Cada fitxa consta d'un títol que } \\
\text { específica el contingut que es } \\
\text { treballarà.(ex: devant- } \\
\text { derrière...) }\end{array}$ \\
\hline $\begin{array}{l}\text { A cada fitxa hi ha dues activi- } \\
\text { tats, una al davant i l'altra al } \\
\text { darrere. }\end{array}$ & $\begin{array}{l}\text { Cada fitxa consta de dues } \\
\text { pàgines. Aquestes es troben } \\
\text { estructurades de la següent } \\
\text { manera: } \\
\text { - Un dibuix d'observació. } \\
\text { - Dues activitats simples. } \\
\text { - Una activitat de grau més } \\
\text { elevat. } \\
\text { - Una activitat complementària } \\
\text { per realitzar amb els pares. }\end{array}$ \\
\hline $\begin{array}{l}\text { No apareix cap resum al final } \\
\text { del quadern, però hi ha alguns } \\
\text { continguts que es van repetint. }\end{array}$ & $\begin{array}{l}\text { En les dues últimes pàgines } \\
\text { apareix un resum dels diversos } \\
\text { continguts tractats al llarg del } \\
\text { curs. }\end{array}$ \\
\hline $\begin{array}{l}\text { Només hi ha una activitat central } \\
\text { on el nen/a ha de treballar el } \\
\text { contingut que se li demana. }\end{array}$ & $\begin{array}{l}\text { Les activitats seguixen sempre } \\
\text { una mateixa estructura i un } \\
\text { grau de dificultat creixent. Els } \\
\text { nens/es passaran de l'observa- } \\
\text { ció d'un dibuix a l'abstracció } \\
\text { dels conceptes per mitjà de } \\
\text { diverses activitats. }\end{array}$ \\
\hline
\end{tabular}

- Integrar l'aprenentatge dins la pròpia realitat escolar procurant que els aprenentatges puguin tenir significativitat real.

- Caldria iniciar l'aprenentatge operatiu en la resolució de problemes, ja que són la continuïtat de les situacions vivencials, per passar de mica en mica als plantejaments abstractes.

- La comprensió operativa sorgiria de la comprensió globalitzant de les operacions i no del treball independent d'operació per operació.

\section{Comparació de dos llibres de text}

A l'hora d'establir comparacions, ens hem centrat en tres aspectes bàsics: el tipus de presentació de l'activitat, el material complementari que es mostra en cada quadern i el tractament que cadascú realitza del terme de l'abstracció. Per realitzar-ho ens hem basat en el llibre de fitxes en català Comptar i escriure i amb el llibre de fitxes francès Maternelle (l'ànàlisi feta la podeu veure a la taula 1 ).

Els dos llibres treballen l'abstracció tant simple com reflexiva, però el llibre francès ho fa d'una manera

\begin{tabular}{|l|l|}
\hline \multicolumn{2}{|c|}{ MATERIAL COMPLEMENTARI } \\
\hline \multicolumn{1}{|c|}{ Ilibre català } & \multicolumn{1}{|c|}{ Ilibre francès } \\
\hline $\begin{array}{l}\text { El llibre no presenta una guia } \\
\text { per al mestre. Aquest haurà de } \\
\text { basar les seves explicacions a } \\
\text { partir dels propis coneixements } \\
\text { i de les diverses indicacions } \\
\text { que apareixen al darrere de } \\
\text { cada activitat. }\end{array}$ & $\begin{array}{l}\text { Al principi del quadern hi ha una } \\
\text { aprentroducción dels divers i coneixements } \\
\text { més, també hi ha d'assolir. A } \\
\text { consells per al mestre que li } \\
\text { seran d'utilitat a l'hora d'expli- } \\
\text { car els diferents continguts. }\end{array}$ \\
\hline $\begin{array}{l}\text { El material complementari } \\
\text { consisteix en dos fulls d'adhe- } \\
\text { sius que el nen/a utilitzarà en } \\
\text { diverses activitats. }\end{array}$ & $\begin{array}{l}\text { No hi ha material complemen- } \\
\text { tari. }\end{array}$ \\
\hline
\end{tabular}

\begin{tabular}{|c|c|}
\hline \multicolumn{2}{|c|}{ TRACTAMENT DE L'ABSTRACCIÓ } \\
\hline Ilibre català & Ilibre francès \\
\hline $\begin{array}{l}\text { L'abstracció es treballa dins de } \\
\text { les mateixes activitats, és a dir, } \\
\text { de forma implícita. } \\
\text { Es pot observar tant l'abstrac- } \\
\text { ció simple com la reflexiva. }\end{array}$ & $\begin{array}{l}\text { L'abstracció es treballa tant de } \\
\text { forma implícita, com de forma } \\
\text { explícita (en les activitats que } \\
\text { els nens han de realitzar a } \\
\text { casa amb els pares). } \\
\text { lgual que en el quadern català, } \\
\text { també es treballa l'abstracció } \\
\text { simple i la reflexiva. }\end{array}$ \\
\hline
\end{tabular}

Taula 1. Aspectes comparatius entre els dos llibres analitzats. 


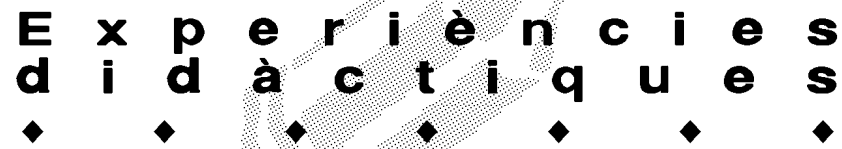

molt més explícita, estructurada i per tant més entenedora per al nen/a.

El llibre francès, a diferència del català, presenta una seqüenciació més clara i ordenada; a més a més, mostra una gran implicació per part dels pares, i afavoreix d'aquesta manera un aprenentatge més significatiu.

Pensem que abans que el mestre (tant el català com el francès) utilitzi aquest material, els nens/es han d'haver realitzat unes tasques inicials per poder lligar els nous continguts amb els coneixements previs pertinents per tal de fer un aprenentatge significatiu. A través d'un material potencialment significatiu, es pretén que el nen/a s'impliqui en tots els sentits, amb ganes, i un cop hagi manipulat, experimentat, vivenciat amb el propi cos... pugui passar a utilitzar el treball en fitxes, ja que això ajudarà el nen/a a realitzar una integració dels continguts per poder arribar a l'abstracció.

\section{Agraïments}

Aquest treball l'hem fet a l'assignatura Utilització de fonts històriques en la Didàctica de les Ciències Socials amb l'assessorament del professor Antoni Gavaldà (Didàctica de les Ciències Socials) i amb l'ajuda del professor Jordi Vallès (Didàctica de les Matemàtiques). A ells volem expressar el nostre sincer agraïment.

\section{Referències bibliogràfiques i bibliografia consultada}

AA.DD. Curs per a l'actuació de l'ensenyament-aprenentatge de les matemàtiques. 2003.

AA.DD. Membres del Xucurruc. La matemàtica vida de les classes d'educació infantil. Ed. Ajuntament de Reus. Regidoria d'Ensenyament. 2001.

AA.DD. Maternelle. Maths. Ed. Bordas. 2000.

FRAILE, J. Comptar i escriure. Els nombres. Ed. Vicens Vives. 1999.

MIRA, M.R. Matemática viva en el Parvulario. Grup Editorial Ceac S.A. Barcelona. 1995.

Adreçes d'Internet:

http://nti.educa.rcanaria.es/cf-infantil/actividap.htm

http://nti.educa. rcanaria.es/rtee/didmat.htm

http: //www.didacticahistoria.com/ccss/manual.htm\#

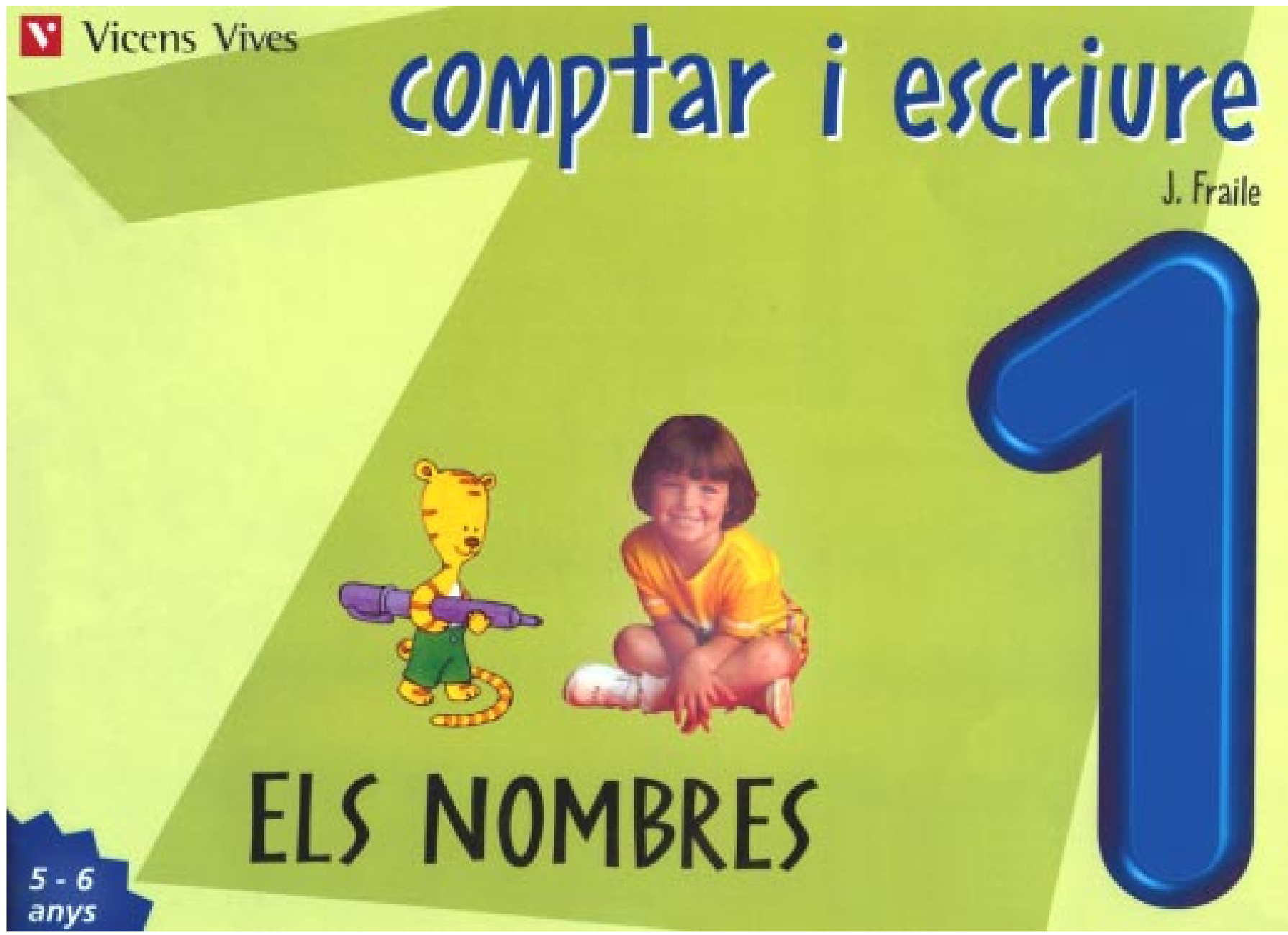

